\title{
ARTículo
}

\section{Paxamarca: un asentamiento inca en el curso medio del río Marañón (provincia de Luya, Amazonas)}

\section{Paxamarca: an Inca settlement in the middle course of the Marañón River (province of Luya, Amazonas)}

\section{Anthony Villar Quintana}

anlex1234@gmail.com

Universidad Nacional

Mayor de San Marcos

\section{Jeff Contreras Soto}

jeff.contreras@pucp.edu.pe

Universidad Nacional Mayor

de San Marcos - Pontificia

Universidad Católica del Perú

\section{Manuel Rojas Tuesta}

rojastuesta0512@gmail.com

Universidad Nacional Toribio

Rodríguez de Mendoza

\section{RESUMEN}

En el presente trabajo, exponemos algunas de nuestras apreciaciones sobre el asentamiento de Paxamarca durante la hegemonía inca, mediante el reconocimiento de edificios típicos del Tahuantinsuyo, en los que destacan kallankas, kanchas y otras estructuras que formaron parte de la denominada arquitectura de poder, ubicadas entre edificios de estilo local. Expresamos, además, la posible importancia del complejo en el control y la organización de un amplio territorio durante el Horizonte Tardío.

Palabras Clave: Paxamarca; Horizonte Tardío; Marañón; arquitectura inca; Tahuantinsuyo.

\section{ABSTRACT}

In this article, we present an evaluation of the Paxamarca settlement during the Inca hegemony, by analyzing typical buildings of the Tahuantinsuyo, in which kallankas, kanchas, and other structures that formed part of the so-called architecture of power and were located among local style buildings stand out. We also suggest the possible importance of the complex in controlling and organizing a wide territory during the Late Horizon.

Keywords: Paxamarca; Late Horizon; Marañón; Inca architecture; Tahuantinsuyo. 


\section{Introducción}

Cada vez son más los investigadores que abordan el estudio del periodo Horizonte Tardío en el territorio de la actual región Amazonas, desde que en 1877 el viajero alemán Ernst Von Middendorf visitó la zona buscando indicios de una presencia incaica. Consideró a Pomacocha como una instalación cercana a Leimebamba, utilizada como puesto militar inca (Schjellerup, 2005).

Posteriormente, Julio C. Tello, durante su expedición arqueológica al Marañón de 1937, visitó Cochabamba, en Chuquibamba, y Chachapoyas, a la cual consideró como nexo entre Huánuco Pampa y Tomebamba debido a la presencia de arquitectura típica cusqueña (Tello, 1956), desde donde las tropas incas habrían partido en la conquista de Leymebamba, Chillchos, Jalca y Kuélap (Tello, 2004).

El avance en las investigaciones sobre el Horizonte Tardío y la hegemonía inca en Amazonas se lo debemos en gran parte a Inge Schjellerup (2005, 2013, 2017, 2018), debido a su estudio de diversos complejos incaicos, como el centro administrativo de Cochabamba y las instalaciones de Tampu Las Lagunas, Tampu de Calla-Calla, Tampu Tajopampa, Tampu Atuén, Tampu Alcaparrosa, Tampu Incensio, Posic e Inca Llacta.

A estos trabajos se suman las contribuciones de otros investigadores, como Peter Lerche (1995), quien registra arquitectura inca con mampostería fina en territorio del subgrupo étnico Chilcho, en el sitio de Puca Huaca, conocido también como Inca Llacta (Muskutt, 2013; Schjellerup, 2017, 2018). Por su parte, Arturo Ruiz demostró la presencia inca en Leimebamba, también mencionada en fuentes etnohistóricas, a través del registro de fragmentos de aríbalos y una estructura que según su descripción correspondería a una kallanka (Ruiz, 1985). Ruiz identificó, además, patrones arquitectónicos inca en Purumllacta de Cheto, provincia de Chachapoyas (Ruiz, 2004). Recientemente, las investigaciones de James Crandall (2017) nos explican los cambios arquitectónicos y sociales producidos bajo el dominio inca y español en Purum Llacta de Soloco.

Tratando de contribuir a las investigaciones referentes al tema, en el presente texto plasmamos algunas de nuestras apreciaciones sobre el asentamiento de Paxamarca, ubicado en la provincia de Luya, Amazonas. Para lo cual, nos basamos en datos de campo referidos principalmente a la arquitectura de estilo inca. A través de estos buscamos aproximarnos a la importancia que tuvo este sitio durante la hegemonía inca.

\section{Ubicación geográfica y medio ambiente}

El complejo arqueológico de Paxamarca se ubica políticamente en territorio de la comunidad de Tulic, anexo del distrito de Pisuquia, provincia de Luya, departamento de Amazonas (figura 1). Emplazado en un área montañosa con abundante floresta tropical, entre los ríos Naranjo (margen derecha) y Congón (margen izquierda), ambos afluentes del río Marañón en su margen derecha.

Esta área se halla sobre el lado oriental de la cordillera andina, en la ecorregión correspondiente a la denominada Amazonia andina (Morales, 1998), Andes amazónicos (Kauffmann y Ligabue, 2003) o Ceja de Selva (Pulgar, 1985). Esta se caracteriza por presentar una diversidad de climas y paisajes de Bosque Pluvial Montano Bajo Tropical, con ambientes cubiertos por un copioso bosque tropical de árboles, arbustos, bejucos, musgos, etc., y tupidos montes de helechos y otros, comúnmente cubiertos por neblinas (Kauffmann y Ligabue 2003), y bajo un clima templado y cálido con temperaturas medias que varían entre $14,5^{\circ} \mathrm{C} \mathrm{y} 25^{\circ} \mathrm{C}$, así como una precipitación anual entre $500 \mathrm{~mm}$ y $4000 \mathrm{~mm}$ (Chamorro, 2017). 

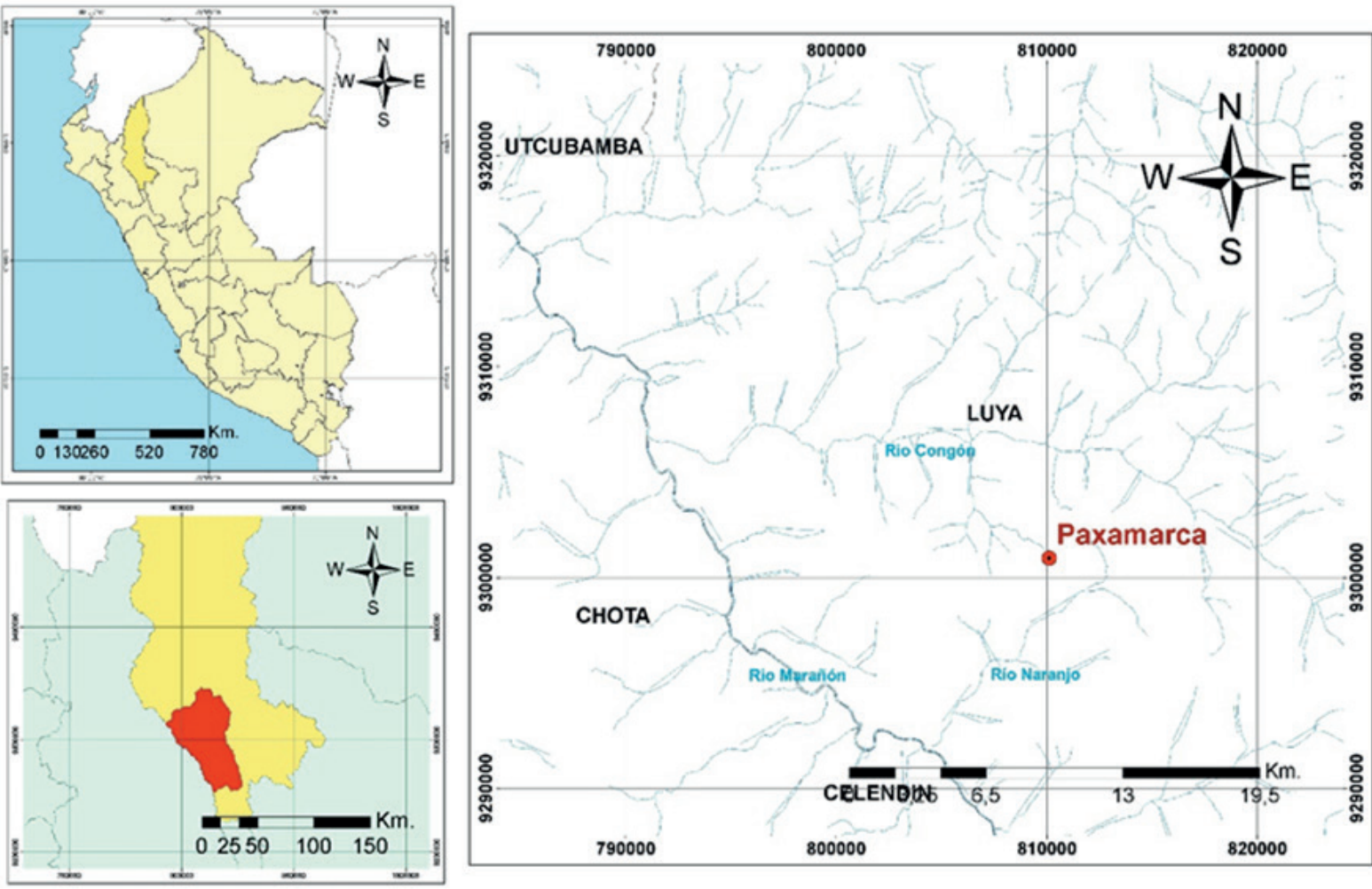

Figura 1. Ubicación del complejo arqueológico de Paxamarca, en la provincia de Luya, Amazonas, Perú

El área abordada en el presente estudio presenta una gran variedad de especies de flora y fauna. La región Amazonas posee alrededor de 3100 especies de flora, un quinto de las registradas en el Perú, entre árboles, arbustos, hierbas, palmeras, helechos y orquídeas (Leo, 2013). Esta área cuenta, además, con diversas especies de fauna, como el colibrí cola espátula (Loddigesia mirabilis), el colibrí pico de espada (Ensifera ensifera), el venado colorado (Mazama americana), el añuje o chosca (Dasyprocta punctata), el majás (Cuniculus paca), el tigrillo (Leopardus pardalis), el oso hormiguero (Myrmecophaga tridactyla), el oso de anteojos (Tremarctos ornatus) y el venado gris (Odocoileus peruvianus). Cabe resaltar que las pieles de estos dos últimos animales sirvieron antiguamente como envoltorios en algunos entierros humanos del Periodo Intermedio Tardío, en la región (Vásquez, Koschmieder y Rosales, 2013).

\section{Antecedentes de investigación}

Las primeras referencias del complejo arqueológico de Paxamarca se las debemos a Juan Bustamante (1984) y a Morgan Davis (1988). El primero definió dos sectores en Paxamarca, ubicados en distintos niveles. En la zona baja registró edificios de estilo inca y en la alta edificios locales caracterizados por su planta circular, informándonos además sobre un documento escrito por el sacerdote alemán Alfredo Palmer Fluquer en 1827, donde se hace mención a Paxamarca como un punto por donde transitaban desde la actual Cajamarca en tiempos incaicos (Bustamante, 1984).

Davis (1988), quien visitó el área en compañía de Juan Bustamante, consideró a Paxamarca como un gran centro urbano y ceremonial de aproximadamente 20 hectáreas $\left(200000 \mathrm{~m}^{2}\right)$, con amplios edificios de planta circular y numerosas estructuras rectangulares, características que demostrarían la dominación inca en el sitio, el cual junto a los sitios de Tulalón y Chicles formarían un solo complejo. 
Posteriormente, Peter Lerche (1996) menciona la existencia de una plaza y edificios ortogonales como indicadores de la presencia imperial inca y su conexión con otros asentamientos que también presentarían edificios de estilo inca, los cuales también fueron mencionados por Davis (1988). Manuel Rojas (2017), durante el XXV Congreso Nacional de Estudiantes de Arqueología, consideró la posible función del sitio como un centro administrativo inca, formando parte de una ruta de tránsito que conectaba a sitios importantes del territorio amazonense, como Kuélap, con el área de Cajamarca, cruzando el rio Marañón.

Notamos así un alto potencial de estudio en el complejo arqueológico de Paxamarca, por lo cual decidimos escribir el presente artículo a modo de introducción a los futuros trabajos que nos propusimos a realizar en el complejo y el área en el que se encuentra inscrito. Presentamos algunos planos del complejo, aproximándonos a su funcionalidad durante el Horizonte Tardío, mediante el reconocimiento de edificios con neto estilo inca como kanchas, kallankas, etc., teniendo en cuenta que la ortogonalidad en la arquitectura amazonense también fue expresada en periodos posteriores, después de la conquista europea.

\section{El complejo de Paxamarca}

Como mencionamos anteriormente, el sitio se halla emplazado en un área montañosa, a una altitud promedio de $2572 \mathrm{msnm}$. En él se observan construcciones de planta circular y ortogonal, correspondientes a edificios de estilo local e inca respectivamente, cuyas paredes fueron construidas mediante piedras lajas de composición pizarrosa unidas con argamasa, logrando así la solidez que caracteriza a esta arquitectura.

Paxamarca constituiría un complejo arqueológico compuesto por los sitios de Paxamarca, Tulalón y Chicles, pues estos tres asentamientos constituían una sola gran área (Davis, 1988). A continuación describiremos brevemente los asentamientos de Paxamarca y Tulalón, ya que hasta el momento no tuvimos la oportunidad de visitar el tercer sitio mencionado.

\section{Paxamarca}

Constituye un asentamiento inca local, con una gran plaza de planta trapezoidal ubicada en su área más llana y definida por un gran muro de contención hacia el norte y edificios ortogonales de claro estilo inca a sus lados este, oeste y sur (figuras 2,3 y 4). Al lado oeste de la plaza, se encuentra un edificio de 18.30 por $9.50 \mathrm{~m}$, orientada de oeste a este, y dividido en dos ambientes por un muro (paralelo a los muros externos este y oeste); contando además con tres vanos de acceso de forma trapezoidal, uno en cada muro, externos y divisorios, alineados entre sí, siguiendo la orientación del edificio (figura 5). A este edificio decidimos nombrar provisionalmente como estructura doble, hasta encontrar un nombre más adecuado.

Este mismo tipo de estructuras fue registrado en algunos asentamientos de la región Amazonas, como Peña Calata (Schjellerup, 2005) y Kuélap (Narváez, 1988), así como en Yantuma, en la sierra de Piura (Astuhuamán, 2008). Otra característica resaltante de la estructura doble observada en Paxamarca constituye un espacio en el exterior de la pared este, al lado derecho (según el observador) del vano de acceso. Se trata de una piedra laja colocada horizontalmente y con un orificio de $3 \mathrm{~cm}$ de diámetro, elaborado perpendicularmente al soporte, cumpliendo la misma función de las abrazaderas horizontales en las portadas del complejo norte de Cochabamba (Schjellerup, 2005). Estos fueron elementos que permitieron asegurar las puertas mediante cuerdas (Gasparini y Margolies, 1977; Kendall, 1976). Cabe resaltar que el lado izquierdo del vano también habría poseído un elemento similar, del cual solo queda una cavidad. 


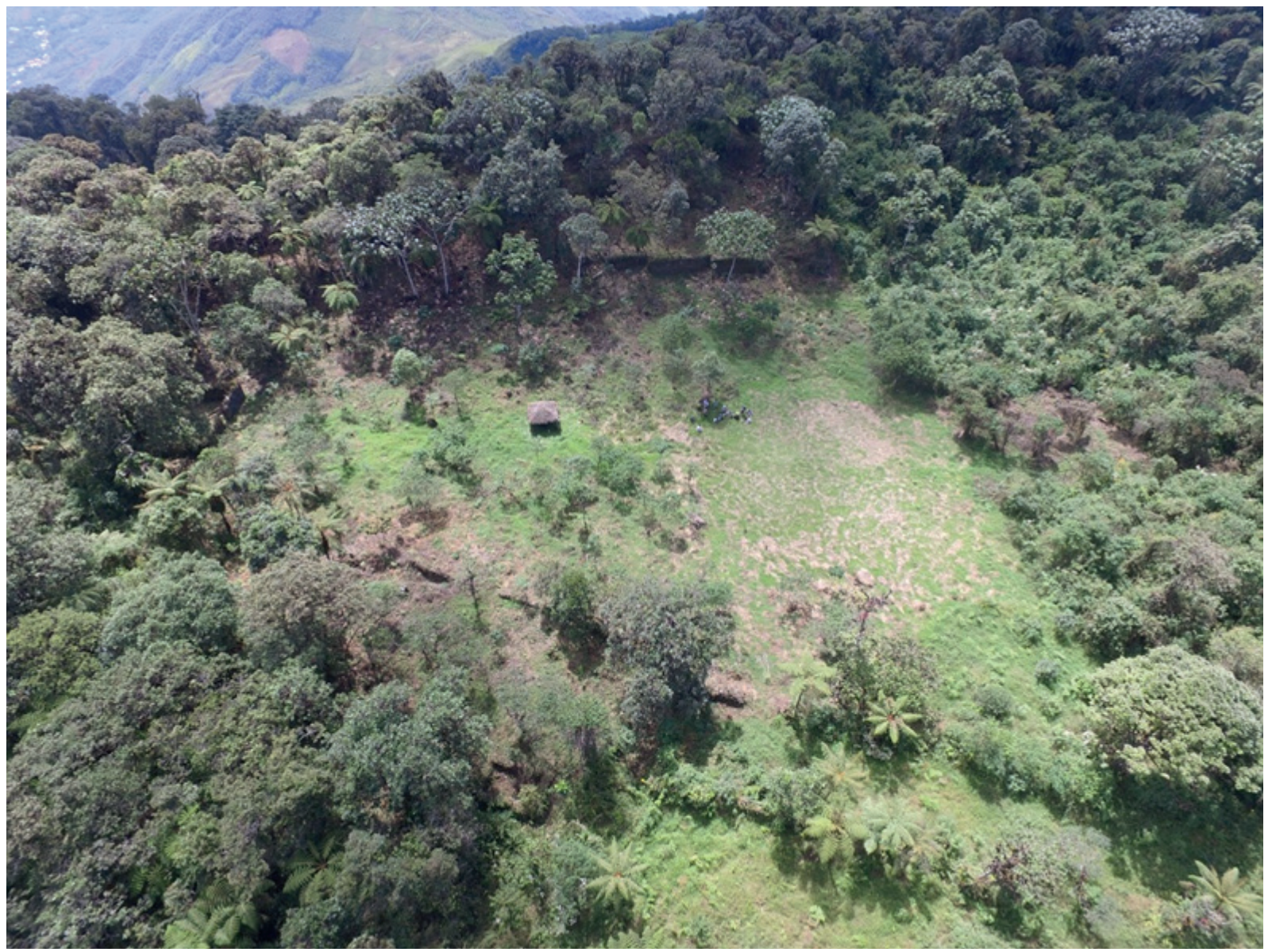

Figura 2. Sector incaico compuesto por la plaza y las estructuras ortogonales, tomada desde el aire con el uso de un dron (Foto: J. Contreras)

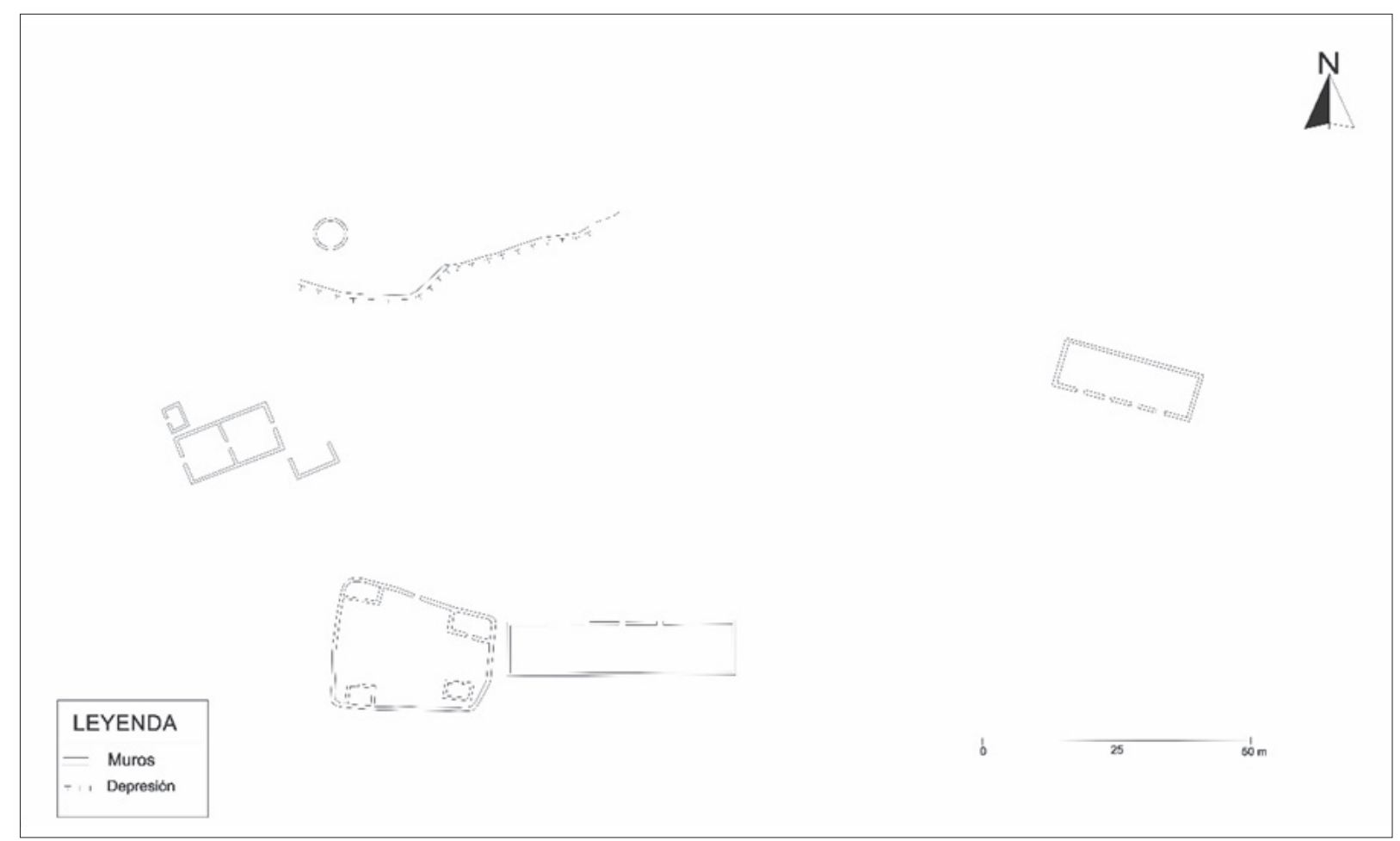

Figura 3. Plano aproximado del sector principal de Paxamarca compuesto por una plaza, una kancha, algunas kallankas y otros edificios ortogonales (Dibujo: A. Villar, M. Rojas y A. Zagaceta). 


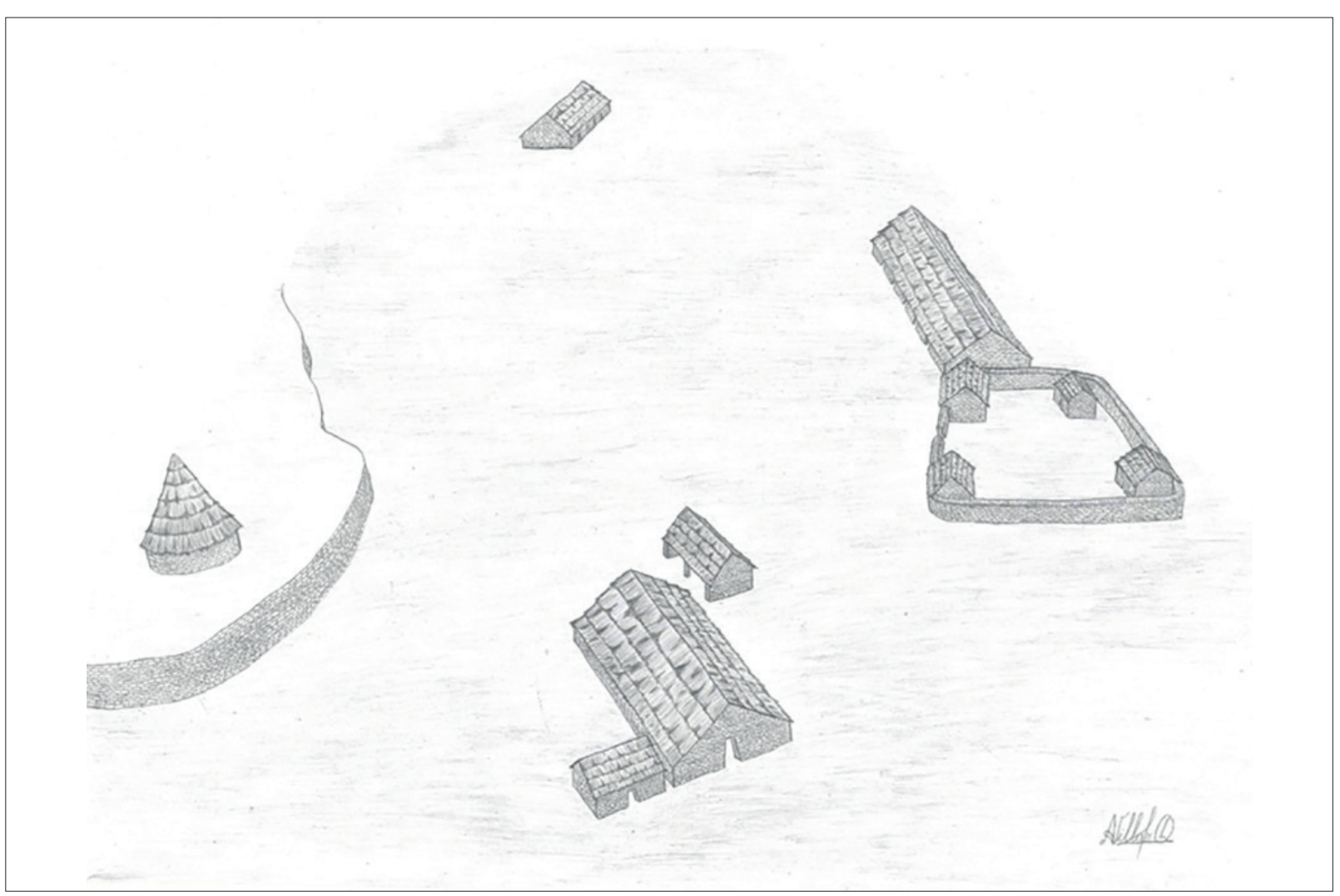

Figura 4. Reconstrucción hipotética del sector principal de Paxamarca, en base al plano aproximado (Dibujo: A. Villar).

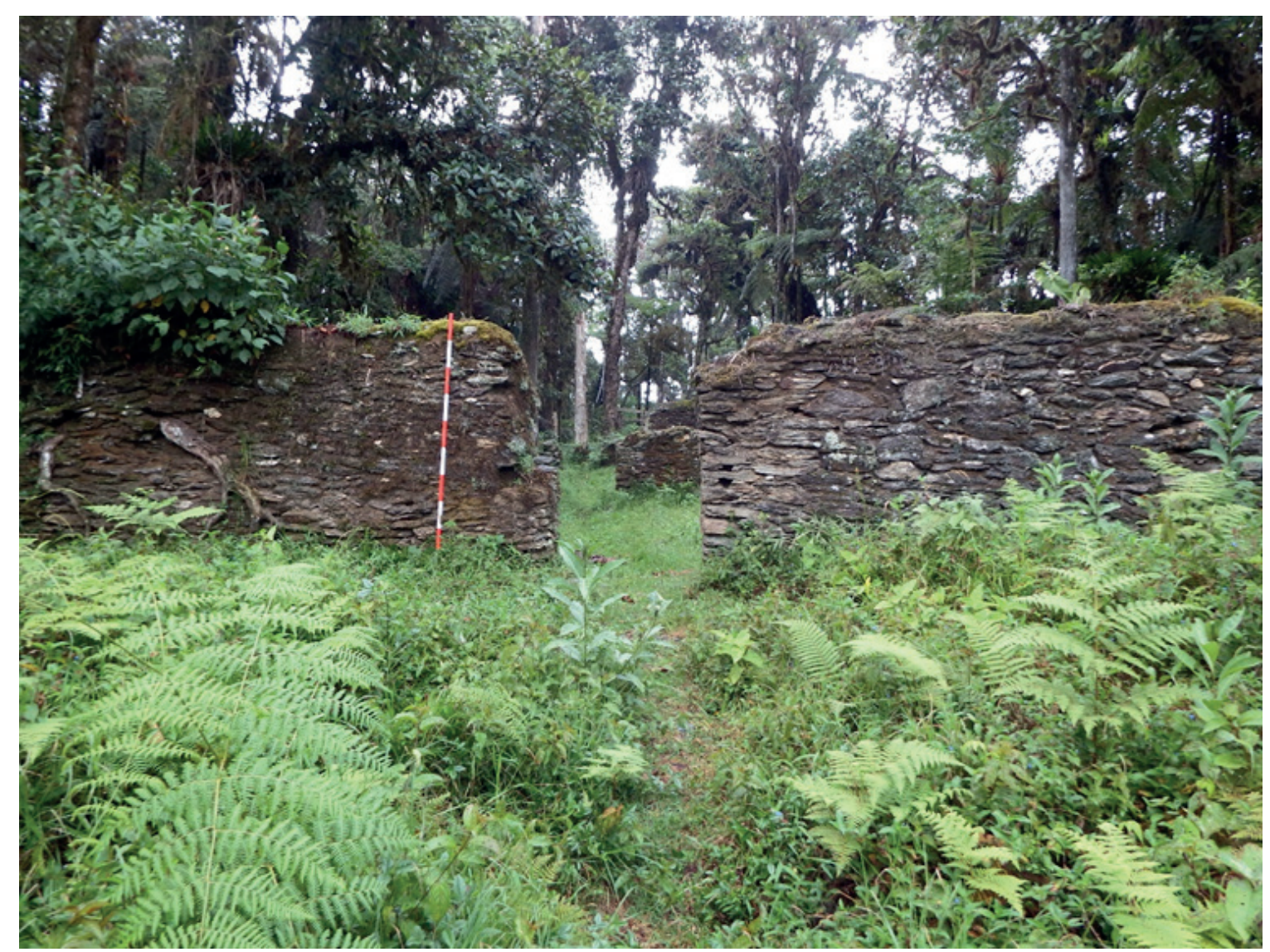

Figura 5. Vano de acceso este de la estructura de doble habitación, el cual a pesar de hallarse deteriorado aun muestra indicios de su forma trapezoidal (Foto: A. Villar) 
Hacia el lado noroeste del edificio descrito se ubica una estructura rectangular de 4.80 por $3.45 \mathrm{~m}$, con un vano de acceso hacia su lado oeste. En sus paredes se pudieron identificar cuatro hornacinas trapezoidales, con un promedio de $0.50 \mathrm{~m}$ de ancho, $0.58 \mathrm{~m}$ de altura y $0.40 \mathrm{~m}$ de profundidad, dos de las cuales se encuentran al lado este mientras que las sobrantes tanto al lado norte como al lado sur.

Por otra parte, hacia el lado sureste de la estructura doble se ubica un edificio rectangular de 8.50 por $3.90 \mathrm{~m}$, orientado de oeste a este, con uno de sus lados abiertos hacia el norte. Según Graziano Gasparini y Luise Margolies (1977), este tipo de edificio sería denominado como masma por Luis Valcarcel y wayrana por Víctor Angles. Asimismo, esta estructura se encontraría muchas veces relacionada a zonas cálidas, y pudo corresponder a un espacio para la realización de trabajos diurnos (Gasparini y Margolies, 1977).

Debido a sus dimensiones alargadas, este edificio habría contado con un pilar en el medio de la fachada, para servir de apoyo a la larga viga de madera que soportaría el peso del techo, como lo indican otros investigadores para este tipo de estructuras (véase Gasparini y Margolies 1977; Protzen, 1992; Hyslop, 2016 [1990]).

Al sur de la plaza se ubica una kancha, compuesta por un muro perimétrico de planta cuadrangular con las esquinas redondeadas, y un vano de acceso dispuesto hacia la plaza. Dicha kancha se halla compuesta por cuatro recintos de planta ortogonal, cada uno con un vano de acceso dispuesto hacia un patio interno. Dos de estos recintos se encuentran en las esquinas noreste y sureste de la kancha, mientras que de los dos recintos restantes, uno se encuentra adosado al lado sur del muro perimétrico y el otro se encuentra próximo y sin contacto directo al lado sureste. Cabe resaltar que la pared del muro perimétrico es más ancha que la de los recintos.

Inmediatamente al este de la kancha se ubica una kallanka de 42.10 por $9.90 \mathrm{~m}$, orientado de este a oeste. Pese a que gran parte de los muros de dicha kallanka se hallan caídos y la maleza no permitía observar con claridad los detalles, se distinguieron tres vanos de acceso y se intuyeron otros dos, todos ubicados en el parámento norte y orientados hacia la plaza.

Asimismo, al este de la plaza se ubica otra kallanka (figura 6) de dimensiones menores: 26.10 por $8.60 \mathrm{~m}$, orientada de noroeste a sureste. Esta kallanka cuenta con cuatro vanos de acceso trapezoidales en su lado sur, los cuales habrían contado con casi $2 \mathrm{~m}$ de altura y $1.44 \mathrm{~m}$ de ancho en la base. En el interior de este edifico aún se observan dos hornacinas trapezoidales (figura 7) en su lado norte, con un promedio de $0.50 \mathrm{~m}$ de ancho en la base, $0.60 \mathrm{~m}$ de altura y $0.55 \mathrm{~m}$ de profundidad. Sobre la base de algunos cálculos determinamos que este lado de la kallanka habría constituido el soporte de un total de ocho hornacinas.

Como se mencionó anteriormente, al lado norte de la plaza se ubica el muro de contención sobre el cual se observaron edificaciones de planta circular con un promedio de $7 \mathrm{~m}$ de diámetro. Asimismo, hacia el lado noreste de la plaza se observaron muchos edificios circulares (figura 8), con diámetros de hasta $10 \mathrm{~m}$; algunos presentan basamentos de $2 \mathrm{~m}$ de altura en promedio. También se observaron edificaciones ortogonales, muchas veces en combinación y asociados con edificios circulares a manera de kanchas, en un estilo inca mixto.

Entre estos edificios también se observaron estructuras rectangulares de pequeñas dimensiones, subdivididas internamente y carentes de vanos de acceso (figura 9). Una de estas estructuras presentaba lo que al parecer sería un ducto de ventilación y/o drenaje (figuras 9 y 10), evidenciando su función como colcas, estructuras donde se habrían almacenado diversos productos. 


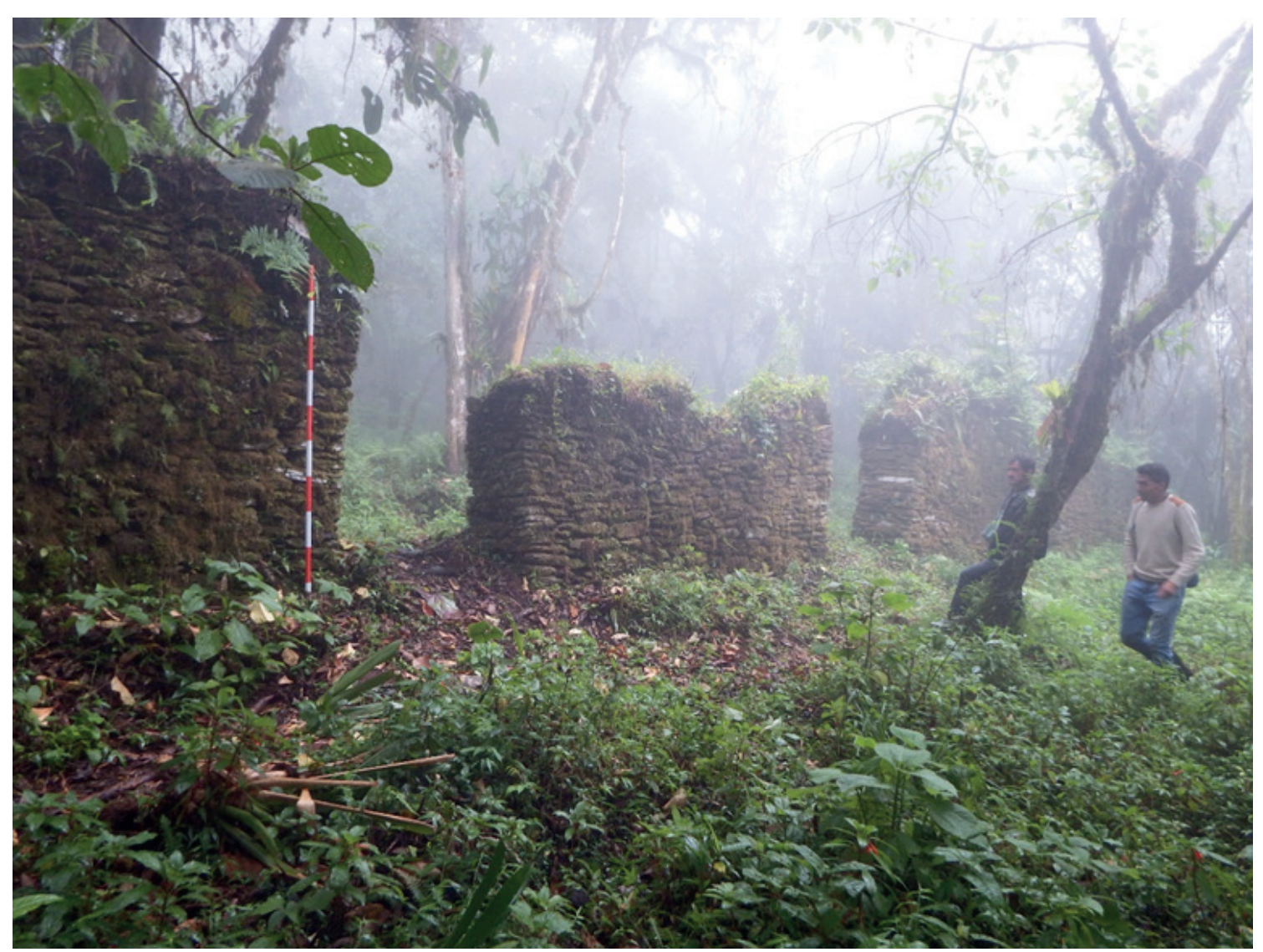

Figura 6. Kallanka ubicada al este de la plaza; nótese los vanos trapezoidales (Foto: A. Villar)

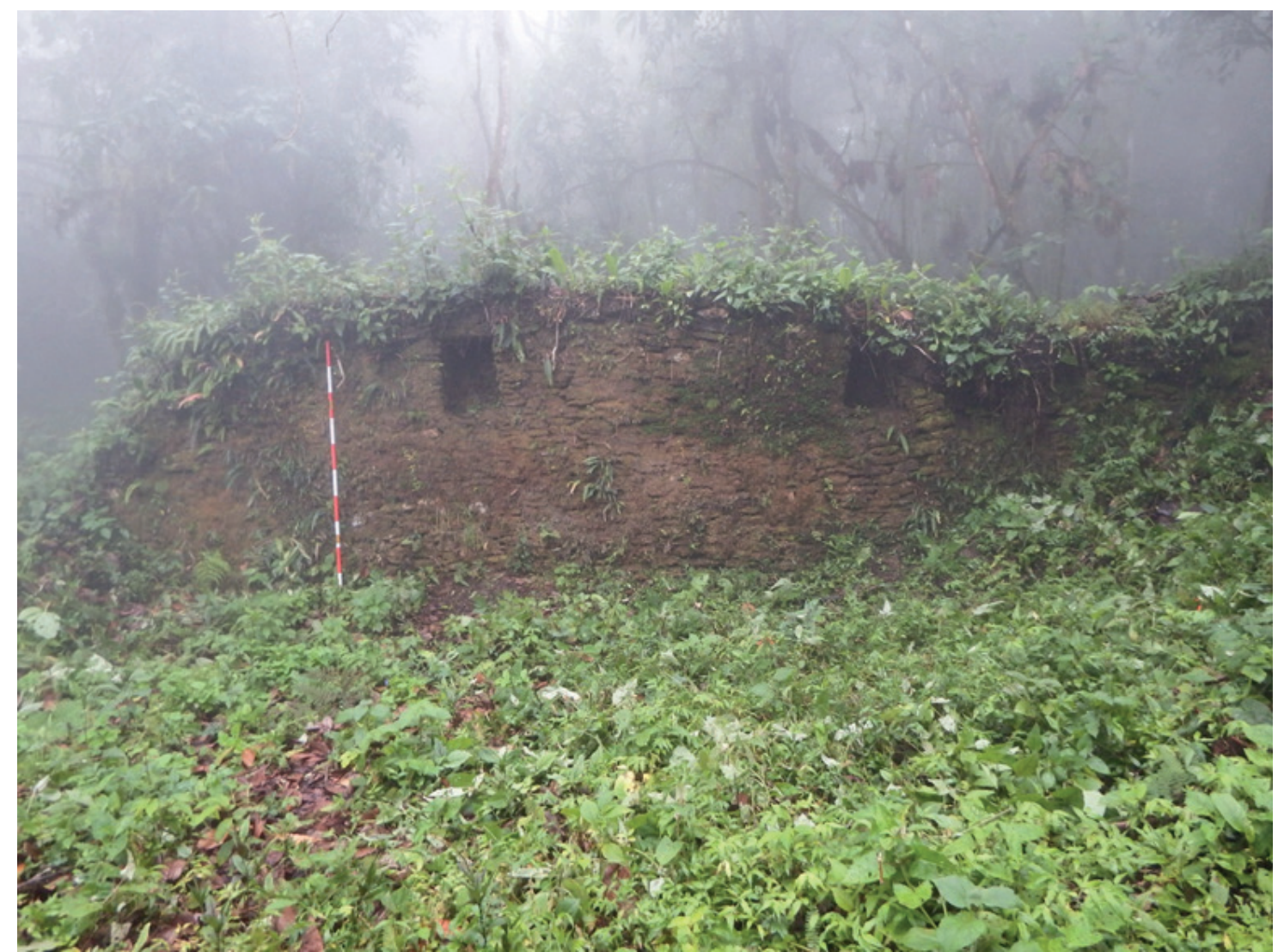

Figura 7. Hornacinas trapezoidales en el interior de la kallanka, ubicada al este de la plaza (Foto: A. Villar) 


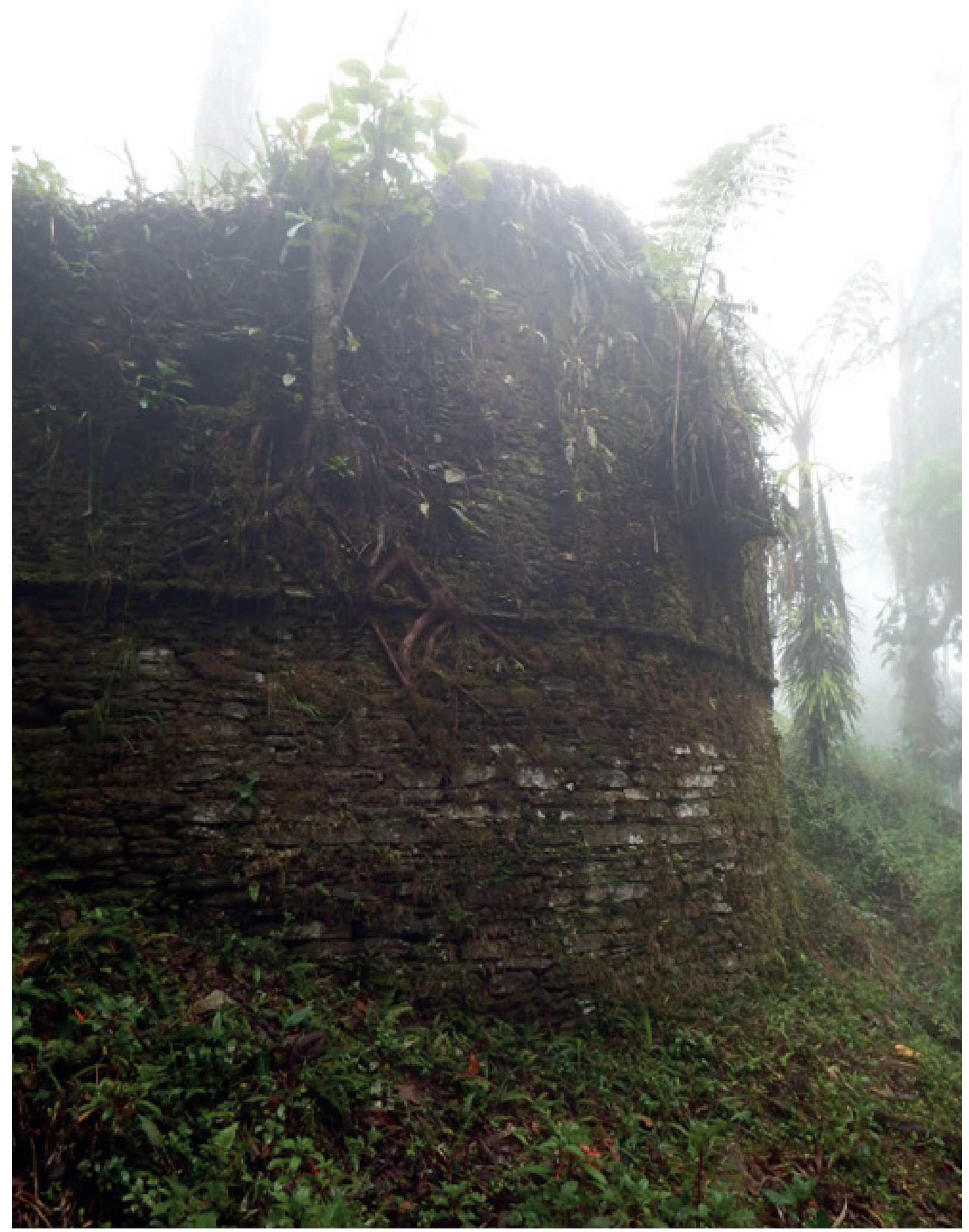

Figura 8. Una de las edificaciones circulares con basamento y cornisas de Paxamarca (Foto: A. Villar) 


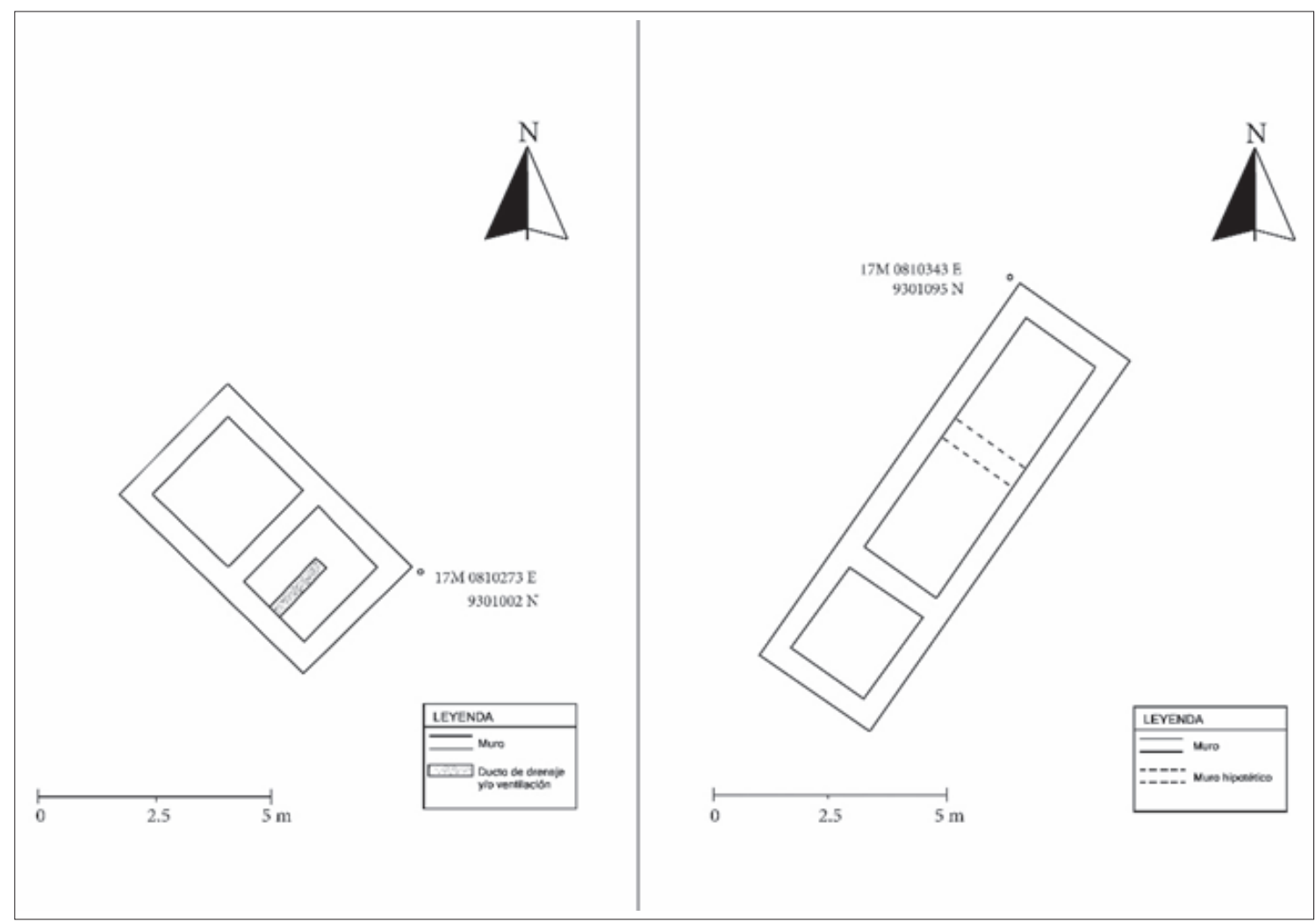

Figura 9. Planos referentes a dos colcas de estilo inca ubicadas en Paxamarca (Dibujo: A. Villar y M. Rojas)

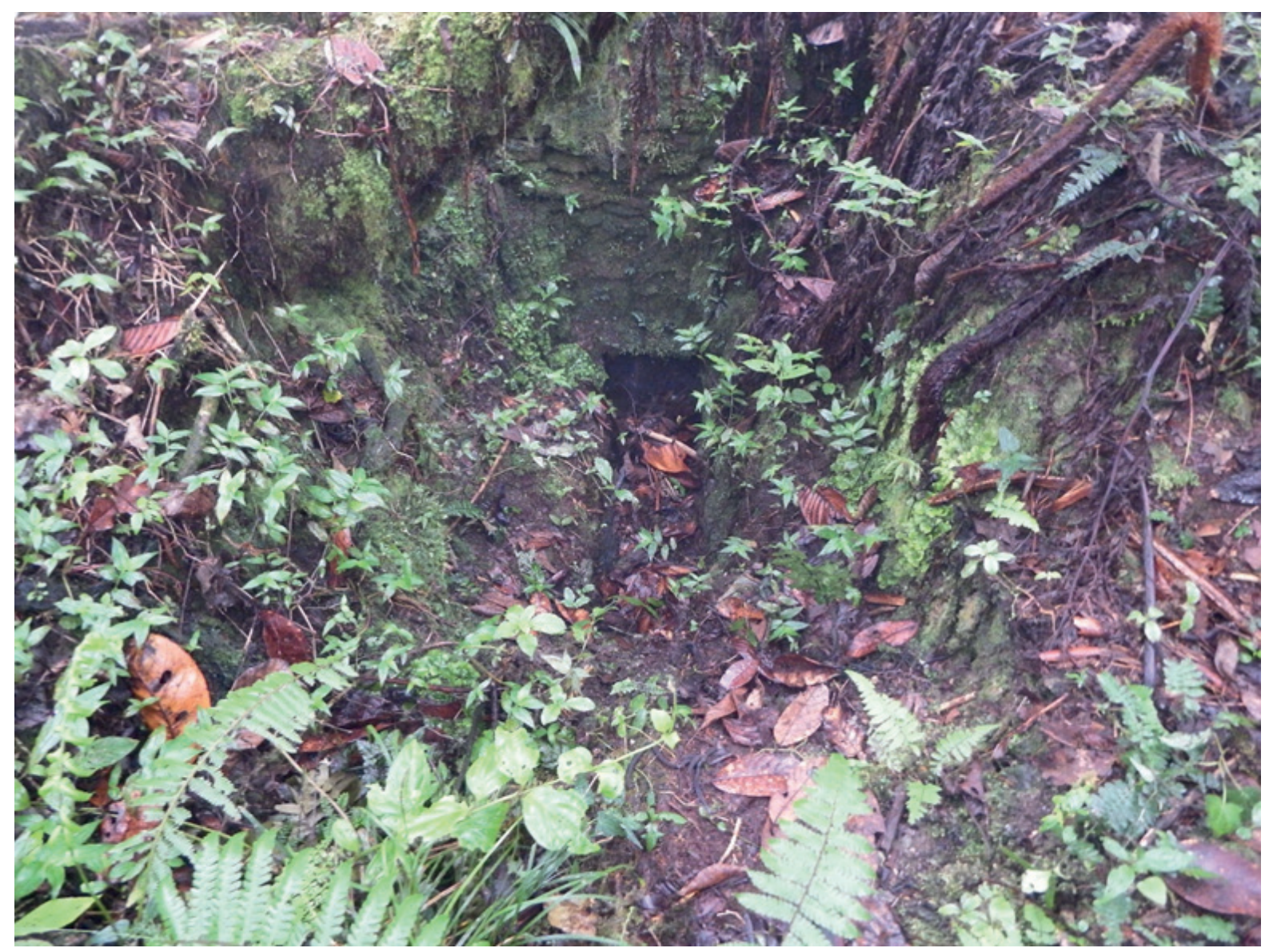

Figura 10. Ducto de ventilación y/o drenaje en una de las colcas de estilo inca en Paxamarca (Foto: A. Villar) 


\section{Tulalón}

Emplazados al sur de Paxamarca, a una altitud de aproximadamente $2380 \mathrm{msnm}$, se encuentran edificios de estilo inca (figura 11) -como una kancha, una estructura doble y un edificio tipo kallanka- y de estilo local, relacionados a edificios de planta circular. Todos construidos con la misma albañilería descrita para los edificios de Paxamarca.

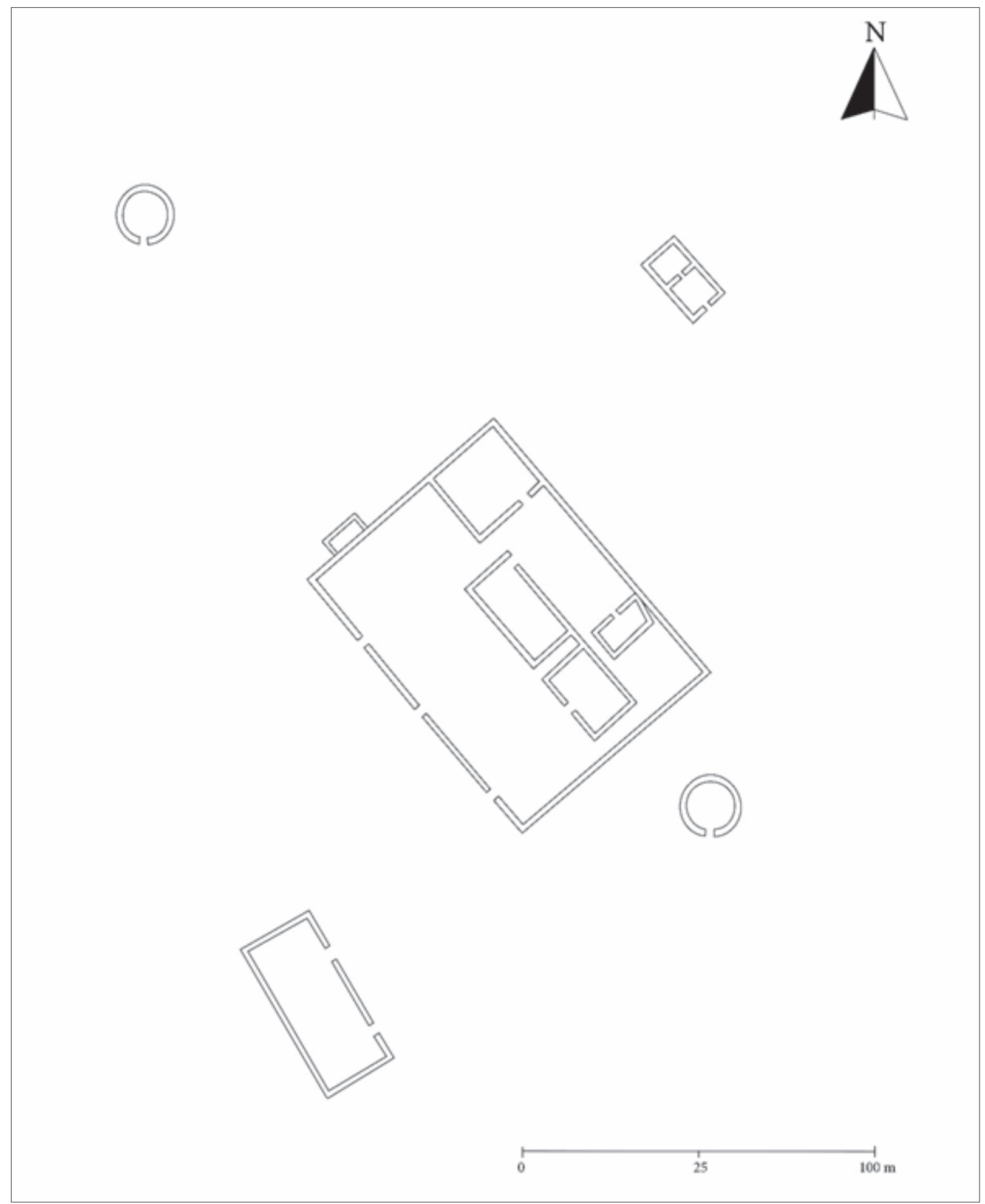

Figura 11. Plano aproximado de Tulalón, compuesto por edificios de estilo inca y local (Dibujo: M. Rojas y R. Rojas) 
La kancha corresponde a un edificio de forma ortogonal con 35 por 47 m y una orientación de sureste a noroeste, conformado por dos patios. En el interior de dicha kancha, observamos algunos detalles como los vanos de acceso trapezoidales (figura 12) y posibles ventanas orientadas hacia el patio más amplio; asimismo, adosado al muro noroeste de la kancha, se encuentra una estructura cuadrangular pequeña de 6 por $2.5 \mathrm{~m}$, la cual pudo haber sido construida para limitar un acceso en ese lado del edificio, como se observa en la kancha de Pucalpa (Schjellerup, 2005), sitio considerado como un sector del centro administrativo de Cochabamba, en el distrito de Chuquibamba (Chachapoyas).

Hacia el norte de la kancha, a una altitud más elevada, se ubica una estructura doble orientada de sureste a noroeste con dimensiones de 6 por $11 \mathrm{~m}$ y vanos de acceso en el lado exterior sureste y en la pared divisoria; ambos se hallan alineados entre sí. Asimismo, aproximadamente a $30 \mathrm{~m}$ al suroeste de la kancha, se encuentra un edificio tipo kallanka, orientado de sureste a noroeste, con dimensiones de 11 por $24 \mathrm{~m}$, el cual contaría con dos vanos de acceso ubicados en la pared noreste.

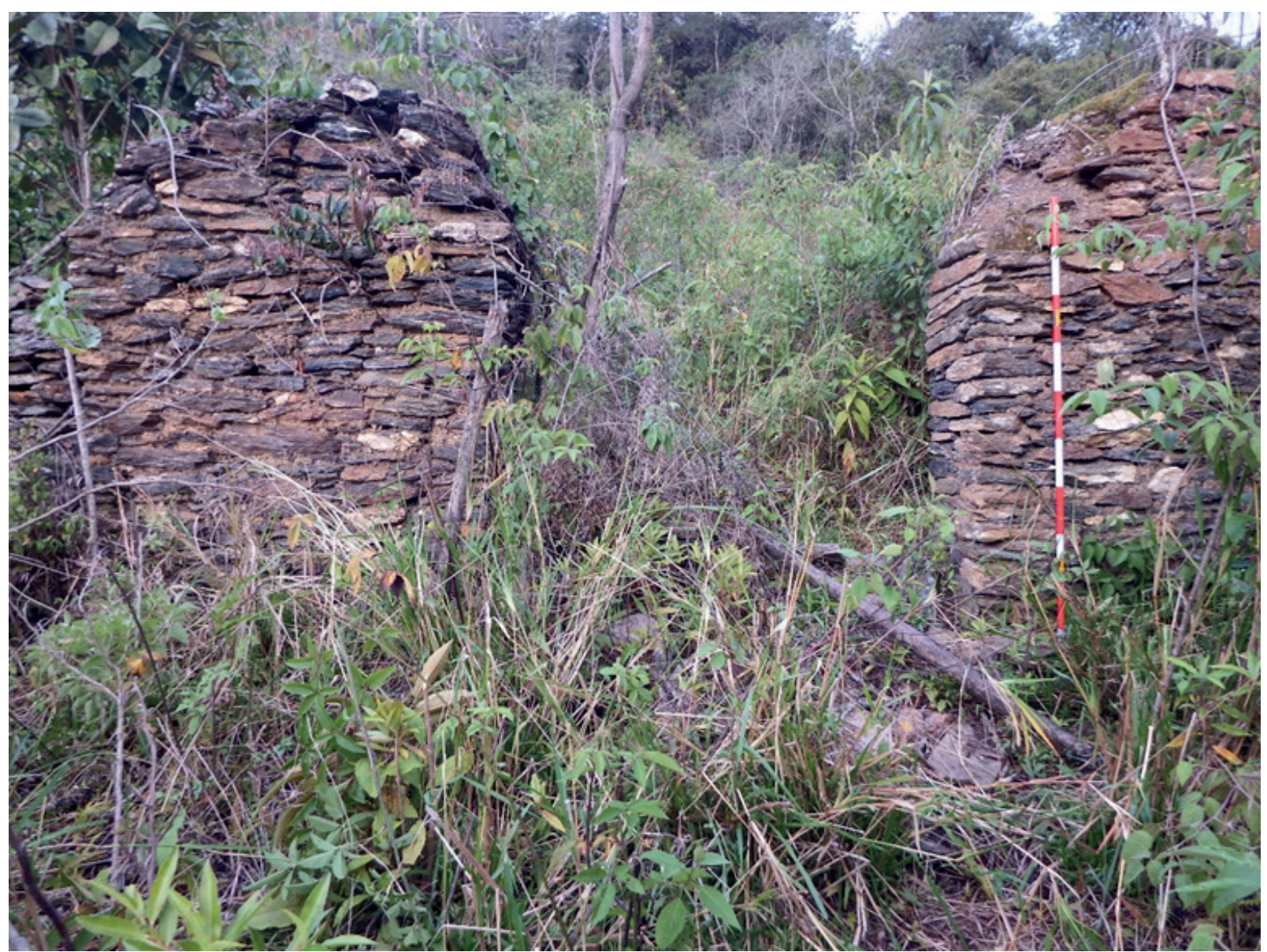

Figura 12. Vano de acceso trapezoidal en una de las estructuras que componen la kancha de Tulalón, la cual sirvió de acceso desde el patio más extenso de dicho edificio (Foto: A. Villar)

\section{Apreciaciones finales}

La importancia del complejo arqueológico de Paxamarca durante la hegemonía inca es expresada a través de sus diversas características, como su gran extensión, abarcando tres asentamientos de considerables dimensiones. El complejo cuenta con un gran espacio cívico-ceremonial (plaza) rodeado por arquitectura de típico estilo inca como kallankas, kanchas, masmas o 
wayranas y colcas, así como otras de estilo local, construidas con el mismo material y técnica, manifestándonos la prevalencia arquitectónica local, aun cuando los diseños corresponderían a influencias o imposiciones inca.

Los edificios de planimetría inca en Paxamarca, descritos en el presente artículo, junto a otro definido por Morgan Davis (1988) como una estructura ortogonal con esquinas ampliamente redondeadas, ubicada sobre una plataforma redonda, nos dan la idea de su similitud con el templo del sol de Ingapirca, en Ecuador. Estas construcciones formarían parte de la denominada arquitectura de poder (véase Gasparini y Margolies, 1977). Lo anterior apoya además la hipótesis propuesta por Manuel Rojas (2017), quien considera la posible función de Paxamarca como un centro administrativo inca.

La existencia de caminos que conducen hacia puntos claves del río Marañón, donde no es tan difícil cruzar hacia Cajamarca (Bustamante, 1984; Davis, 1988), resaltando entre estos el llamado paso del inca, indicaría otro aspecto mencionado previamente por Manuel Rojas (2017), correspondiente a la conexión desde las actuales tierras cajamarquinas con los distintos asentamientos en zonas correspondientes a la cuenca del Utcubamba como Kuélap, atravesando el complejo de Paxamarca. Esta es una idea que apoyamos con los reportes de caminos empedrados entre Kuélap y el área donde se ubica Paxamarca (Davis, 1988; Gates, 1997). Una de estas rutas atravesaría el abra Yumal, un paso ubicado inmediatamente al sur del pico Shubet, el más alto de la zona, con una altitud de 3700 msnm (Morgan Davis, 1988). Esta ruta uniría distintos asentamientos como Changalí, La Fila y Llaucán, lugares donde Carol Rojas y Nathaniel VanValkenburgh (2018) registraron arquitectura y cerámica de influencia inca.

El presente estudio resalta, además, la marcada ocupación e importancia de Kuélap durante el Horizonte Tardío, expresada principalmente en la alfarería (Ruiz, 2009 [1972], 2013) y la arquitectura (Langlois, 1939; Narváez, 1988, 2013; Kauffmann, 2013). Todo apoya al postulado que considera a Paxamarca como un nexo importante en la ruta Kuélap-Cajamarca, existiendo además otras conexiones hacia el sur, como con el centro administrativo inca de Cochabamba, a través de una ruta paralela al río Marañón.

Esta última ruta continuaría hacia el norte, rumbo a la actual provincia de Utcubamba, siguiendo caminos utilizados anteriormente y donde se observan pinturas rupestres de estilo inca en lugares como Yamón (véase Ruiz, 1998; Olivera, 2015) y Calpón (Villar, 2018). En esta ruta podrían existir muchos otros asentamientos con arquitectura y otros materiales culturales de influencia inca, lo cual es apoyado con la existencia de topónimos referentes a algunos pueblos en dicha área como Selcho Cuzco y Yungasuyo.

Contextualizar a Paxamarca dentro del sistema implantado por los incas en esta parte del Tahuantinsuyo, aún constituye una tarea pendiente. Sin embargo, partimos de la hipótesis de su funcionamiento como centro administrativo o asentamiento de mayor jerarquía en el territorio, como Cochabamba (Schjellerup, 2005), Posic, Pukarumi, Inca Llacta (Schjellerup, 2018,), Purumllaqta de Cheto (Ruiz, 2004) y Purumllaqta de Soloco (Crandall, 2017), debido a sus características similares a centros administrativos de gran escala como Pumpu, Huanuco Pampa y Aypate.

Sin embargo, una de las formas de lograr responder a la interrogante relacionada a la funcionalidad de Paxamarca y a su organización en relación con otros complejos o asentamientos dentro de la llamada provincia inca de Amazonas, correspondería a un registro planimétrico minucioso, quizá acompañado de excavaciones arqueológicas, tratando de identificar las 
distintas instituciones inca, características de centros administrativos, así como el registro de asentamientos circundantes ocupados durante el Horizonte Tardío, ya mencionados por Morgan Davis (1988), como Tálape, Pueblo Alto, Pircapata y Machu Llaqta, con el objetivo de identificar la relación de estos frente al complejo de Paxamarca.

\section{Agradecimientos}

Agradecemos a la Asociación en Defensa del Patrimonio Cultural Paxamarca-Tulic, a su presidente el señor Antero Zagaceta Rocha y a los integrantes de dicha asociación por brindarnos las facilidades, acompañamiento y asistencia en el sitio arqueológico. A Juan Bustamante Vallejo por brindarnos información inédita de su autoría; así como a Romel Rojas Servan, Edith Tuesta Arce, Teófilo Cruz Latorre, Leyla Irigoin Silva y Wilder Sifuentes Buelot.

\section{Bibliografía}

Astuhuamán, César (2008). The organisation of the Inca provinces within the highlands of Piura, northern Peru. (tesis de doctorado). Institute of Archaeology, University College London, Londres.

Bustamante, Juan (1984). Paxamarca, cultura Chachapoyas. Documento inédito (Manuscrito).

Chamorro, Anderson (2017). Paisaje cultural valle alto del Utcubamba. Lima: Ministerio de Cultura, Dirección de Paisaje Cultural.

Crandall, James (2017). "El desarrollo espacial de las comunidades Chachapoyas bajo la dominación colonial inka y española". Boletín de Arqueología PUCP, (23): 283-311.

Davis, Morgan (1988). Chachapoyas: The cloud people. Ontario: University of Sudbury.

Gasparini, Graziano y Luise Margolies (1977). Arquitectura inka. Caracas: Centro de Investigaciones Históricas y Estéticas, Facultad de Arquitectura y Urbanismo, Universidad Central de Venezuela.

Gates, Carlos (1997). Historia inédita de los Chachapoyas. Lima: Facultad de Turismo y Hotelería, Universidad San Martín de Porres.

Hyslop, John (2016 [1990]). Asentamientos planificados Inka. Lima: Ediciones Copé.

Kauffmann, Federico (2013) "Los Chachapoyas: orígenes y trayectoria cultural”. Los Chachapoyas (pp. 41-79) Lima: Banco de Crédito del Perú.

Kauffmann, Federico y Giancarlo Ligabue (2003). Los Chachapoya(s): moradores ancestrales de los Andes amazónicos peruanos. Lima: Universidad Alas Peruanas.

Kendall, Ann (1976). "Descripción e inventario de las formas arquitectónicas inca". Revista del Museo Nacional, (42): 13-96.

Langlois, Louis (1939-1940). "Utcubamba, investigaciones arqueológicas en este valle del departamento de Amazonas". Revista del Museo Nacional, (1): 33-72; (2): 191-249.

Leo, Mariella (2013). "Los Andes amazónicos: ecología, flora y fauna". Los Chachapoyas (pp. 15-26). Lima: Banco de Crédito del Perú.

Lerche, Peter (1995). Los Chachapoya y los símbolos de su historia. Lima: s/e.

Lerche, Peter (1996). Chachapoyas. Guía de viajeros. Lima: s/e.

Morales, Daniel (1998). Historia arqueológica del Perú (del paleo-lítico al imperio Inca). Compendio Histórico del Perú. Lima: Editorial Milla Batres.

Muscutt, Keith (2013). "Vira Vira y otros sitios arqueológicos comarcanos Chachapoyas". Los Chachapoyas (pp. 75-78). Lima: Banco de Crédito del Perú.

Narváez, Luis Alfredo (1988). "Kuélap: Una ciudad fortificada en los Andes Nororientales de Amazonas, Perú". I Simposium: Arquitectura y Arqueología. Pasado y futuro de la construcción en el Perú (pp. 115-142). Chiclayo: Universidad de Chiclayo.

Narváez, Alfredo (2013). Kuélap: Cetro del poder político religioso de los Chahapoyas. Los Chachapoyas (pp. 4163). Lima: Banco de Crédito del Perú. 
Olivera, Quirino (2015). El patrimonio arqueológico y sus incidencias en la comunidad de Bagua, AmazonasPerú (tesis para optar el título de Doctor en Historia del Arte y Gestión Cultural en el Mundo Hispánico). Universidad Pablo de Olavide, Sevilla.

Protzen, Jean-Pierre (1992). Arquitectura inca. Los reinos preincaicos y los incas. Barcelona: Lunwerg editores.

Pulgar, Javier (1985). Las tres selvas del Antisuyo. Boletín de Lima (39): 59-72.

Rojas, Carol y Nathaniel VanValkenburgh (2018). Informe final del Proyecto de Investigación Arqueológica. Paisajes Arqueológicos de Chachapoyas (PACHA-2018). Cuenca del Río Utcubamba, Departamento de Amazonas. FASE 1, Temporada 2 - Continuación de prospección y excavación de pozos de prueba.

Rojas, Manuel (2017). "Paxamarca: Un asentamiento chacha-inca, en la región Amazonas". XXV Congreso Nacional De Estudiantes de Arqueología. Universidad Nacional De Trujillo (pp. 26-28). Trujillo: Universidad Nacional de Trujillo.

Ruiz, Arturo (1985). “Los monumentos arqueológicos de Leimebamba”. Boletín de Lima (42): 69-82.

Ruiz, Arturo (1998). “Antigüedad del hombre en Luya se remonta a unos 4 mil años”. El Torreón. 2 (11): 4-5.

Ruiz, Arturo (2004). "Purumllacta: Un centro administrativo incaico en Chachapoyas". Investigaciones Sociales, 8 (13): $73-84$.

Ruiz, Arturo (2009 [1972]). La alfarería de Kuelap: tradición y cambio (No. 4). Lima: Avqi Ediciones.

Ruiz, Arturo (2013). “La cerámica Kuélap”. Los Chachapoyas (pp. 105-107). Lima: Banco de Crédito del Perú.

Schjellerup, Inge (2005). Incas y españoles en la conquista de los Chachapoya. Lima: Pontificia Universidad Católica del Perú e Instituto Francés de Estudios Andinos.

Schjellerup, Inge (2013). "Posic y otros sitios arqueológicos comarcanos". Los Chachapoyas (pp. 80-82). Lima: Banco de Crédito del Perú.

Schjellerup, Inge (2017). "La provincia inka de Chachapoyas”. Boletín de Arqueología PUCP, (23): 259-281.

Schjellerup, Inge (2018). "Sobre las montañas, hacia la ceja de selva: estrategias e impacto de los incas en la región Chachapoyas". El Imperio Inka (pp. 653-678). Lima: Fondo Editorial de la Pontificia Universidad Católica del Perú.

Tello, Julio (1956). Arqueología del valle del Casma. Culturas: Chavín, Santa o Huaylas Yunga y Sub-Chimú, volumen 1. Lima: Publicación Antropológica del Archivo "Julio C. Tello" de la Universidad Nacional Mayor de San Marcos.

Tello, Julio (2004). Arqueología de Cajamarca: expedición al Marañón, 1937. Serie: Clásicos Sanmarquinos. COFIDE. Lima: Centro Cultural de la Universidad Nacional Mayor de San Marcos.

Vásquez, Víctor, Klaus Koschmieder y Teresa Rosales (2013). “Uso de pieles de mamíferos andinos en entierros humanos de los Chachapoya, Provincia de Luya-Departamento de Amazonas". Archaeobios, 1 (7): 22-35.

Villar, Anthony (2018). Manifestaciones rupestres en Amazonas durante el Horizonte Tardio: La conquista incaica plasmada sobre rocas. XIII Coloquio de Estudiantes de Arqueología. Lima: Pontificia Universidad Católica del Perú.

Presentado: 29 junio 2019

Aceptado: 19 setiembre 2019

Publicado online: 15 julio 2020 
